\title{
Role of antiarrhythmic drugs: frequent implantable cardioverter- defibrillator shocks, risk of proarrhythmia, and new drug therapy.
}

\author{
Christopher Droogan \\ Main Line Health Heart Center \\ Chinmay Patel \\ Main Line Health Heart Center \\ Gan-Xin Yan \\ Thomas Jefferson University \\ Peter R Kowey \\ Main Line Health Heart Center
}

Follow this and additional works at: https://jdc.jefferson.edu/medfp

Part of the Cardiology Commons, and the Medical Genetics Commons

Let us know how access to this document benefits you

\section{Recommended Citation}

Droogan, Christopher; Patel, Chinmay; Yan, Gan-Xin; and Kowey, Peter R, "Role of antiarrhythmic drugs: frequent implantable cardioverter-defibrillator shocks, risk of proarrhythmia, and new drug therapy." (2011). Department of Medicine Faculty Papers. Paper 53.

https://jdc.jefferson.edu/medfp/53

This Article is brought to you for free and open access by the Jefferson Digital Commons. The Jefferson Digital Commons is a service of Thomas Jefferson University's Center for Teaching and Learning (CTL). The Commons is a showcase for Jefferson books and journals, peer-reviewed scholarly publications, unique historical collections from the University archives, and teaching tools. The Jefferson Digital Commons allows researchers and interested readers anywhere in the world to learn about and keep up to date with Jefferson scholarship. This article has been accepted for inclusion in Department of Medicine Faculty Papers by an authorized administrator of the Jefferson Digital Commons. For more information, please contact: JeffersonDigitalCommons@jefferson.edu. 


\section{As submitted to: \\ Heart Failure Clinics}

And later published as:

Role of Antiarrhythmic Drugs:

\section{Frequent ICD Shocks, Risk of Proarrhythmia, and New Drug Therapy}

\section{Volume 7, Issue 2 , Pages 195-205, April 2011}

\section{doi:10.1016/j.hfc.2010.12.003}

Christopher Droogan ${ }^{1,}$, DO, FACC Chinmay Patel ${ }^{2}$, MD, Gan-Xin Yan ${ }^{1,3}$, MD, PhD, and

$$
\text { Peter R. Kowey }{ }^{1,3} \text {, MD, FAHA }
$$

${ }^{1}$ Attending Cardiologist, Main Line Health Heart Center and Lankenau Hospital, Wynnewood, PA, USA

2 Cardiology Fellow, Main Line Health Heart Center and Lankenau Hospital, Wynnewood, PA, USA

${ }^{3}$ Professor of Medicine, Jefferson Medical College, Thomas Jefferson University, Philadelphia, PA, USA and Lankenau Institute for Medical Research, Wynnewood, PA, USA 
Key words: implantable cardioverter defibrillator, ventricular arrhythmia, antiarrhythmic drug therapy, adjuvant therapy, ICD shocks

\section{Address correspondence to:}

Peter R. Kowey, M.D.

Main Line Health Heart Center

100 Lancaster Avenue, MOBE 558

Wynnewood, PA 19096, USA

Tel: 484-476-2682; Fax: 484-476-1658; E-mail: koweyp@mlhs.org

Chinmay P. Patel

Main Line Health Heart Center

100 Lancaster Avenue, MOBE 558

Wynnewood, PA 19096, USA

Tel: 484-476-2682; Fax: 484-476-1658; E-mail: patelc@mlhs.org

Gan-Xin Yan

Main Line Health Heart Center

100 Lancaster Avenue, MOBE 558

Wynnewood, PA 19096, USA

Tel: 484-476-2682; Fax: 484-476-1658; E-mail: yanganxin@ comcast.net

Christopher Droogan.

Main Line Health Heart Center 
100 Lancaster Avenue, MOBE 356

Wynnewood, PA 19096, USA

Tel: 610-649-7625; Fax: 610-649-3362; E-mail: drooganc@ mlhs.org

Acknowledgement: None

Funding Source: None

Disclosure: None 


\begin{abstract}
The Implantable Cardioverter Defibrillator (ICD) has become the standard of care in patients with ischemic and non-ischemic cardiomyopathy who are at high risk for arrhythmic events and sudden cardiac death. Recurrent ventricular arrhythmias are common after ICD implantation and the majority of ICD recipients receive one or more shocks within a year of implantation. Although ICDs save lives, the shocks from these devices are associated with profound physical, emotional and psychological trauma, increased morbidity, and poor quality of life. More than half of these patients receive adjuvant antiarrhythmic drug therapy to circumvent episodes of recurrent ventricular and supraventricular arrhythmia. Electrical storm is also common in this high risk population and requires prompt therapeutic intervention with antiarrhythmic drug therapy. Evidence suggests that antiarrhythmic drugs including $\beta$-blockers, sotalol, amiodarone and azimilide, are effective at reducing the shock burden in ICD patients. Although, some antiarrhythmic drugs can interfere with proper ICD function, cautious administration and subsequent monitoring with adjustment of device algorithms can help curtail this problem. Data supporting the need for and potential risk-benefits of adjuvant antiarrhythmic drug therapy in ICD patients are described in this paper.
\end{abstract}

\title{
Synopsis
}

The Implantable Cardioverter Defibrillator (ICD) has become standard of care in patients with ischemic and non-ischemic cardiomyopathy. Although ICD saves life, ICD shocks are emotionally and physically debilitating. Adjuvant antiarrhythmic drug therapy with $\beta$ blockers, sotalol, amiodarone and azimilide is effective in preventing ICD shocks. The 
article examines benefits, pitfalls of adjuvant antiarrhythmic drug therapy in patients with an ICD.

\section{Introduction}

Use of Implantable Cardioverter Defibrillators (ICD) have revolutionized the care of patients with ischemic and non-ischemic cardiomyopathy. ${ }^{1,2}$ The primitive ICD introduced in the 1980 s by Mirowski and colleagues has become much more sophisticated with programming capabilities, atrial and left ventricular leads, antitachycardia pacing (ATP) algorithms, bi-ventricular pacing and cardioverting and defibrillating shocks. ${ }^{1,3}$ Similarly, indications for ICD implantation are expanding as well. ${ }^{4}$ Assessment for eligibility of an ICD implantation is considered one of the integral parts of management of cardiomyopathy patients due to mortality benefits. ${ }^{1,2}$ Consequently, the number of ICD implantations has increased significantly in the last decade with a concurrent decrease in the use of stand-alone antiarrhythmic drugs for ventricular arrhythmia indications. ${ }^{5-7}$

The ICD prevents sudden cardiac death (SCD) by terminating the episodes of ventricular tachycardia (VT) or ventricular fibrillation (VF), delivering ATP therapy or ICD shock. Therefore, patients with ICD typically receive one or more ICD therapies for spontaneous arrhythmias following implantation. ${ }^{1,8}$ Despite the technological evolution of ICD systems, more than $20 \%$ of shocks that are delivered are due to supraventricular arrhythmia and are categorized as "inappropriate". $9-11$ ICD shocks are physically and

emotionally painful and most patients dread future shocks. ${ }^{12}$ Many patients experience symptoms such as dizziness, palpitations, nervousness, flushing or even syncope before 
receiving an ICD shock. ${ }^{13}$ A higher incidence of depression and poor quality of life has been reported in patients who have received one of more ICD shocks, and adverse psychological outcomes directly correlate to the number of ICD shocks. ${ }^{14-16}$

Several anti-arrhythmic drugs have been shown to reduce ICD therapies including shocks. Upward of $70 \%$ patients end up receive adjuvant antiarrhythmic drug therapy for this indication. ${ }^{17,18}$ This was best exemplified in the device arm of the Antiarrythmic versus Implantable Defibrillator (AVID) trial. ${ }^{19}$ About $18 \%$ patients in the ICD arm of the AVID trial had to be started on adjuvant antiarrhythmic drug therapy (amiodarone $42 \%$, sotalol $21 \%$, and mexiletine $20 \%$ ) to reduce frequent ICD shocks and to prevent recurrent ventricular arrhythmia. ${ }^{19}$ Adjuvant antiarrhythmic drug therapy in these crossover patients reduced the one year arrhythmia event rate from $90 \%$ to $64 \%$. Potential benefits, pitfalls, need for caution and the clinical trials of adjuvant antiarrhythmic drugs in ICD implanted patients will be discussed in this review.

\section{Clinical trials supporting the efficacy of adjuvant antiarrhythmic drug therapy}

Major clinical trials establishing the role of adjuvant antiarrhythmic drugs and their principle outcomes are listed in table 1. The majority of patients enrolled in these trials received an ICD for secondary prevention of SCD or a documented episode of VT/VF.

Sotalol was one of the first antiarrhythmic drugs tested for such an indication by Pacifico et al. ${ }^{20}$ In this double-blind prospective multicenter trial, 302 patients with ICDs were randomized to receive either $160-320 \mathrm{mg}$ of $\mathrm{d}, 1-$ sotalol $(\mathrm{n}=151)$ or matching 
placebo $(n=151)$ and were followed for 12 months. In this study, compared to placebo, treatment with sotalol led to a $48 \%$ risk reduction of all-cause mortality and delivery of first shock for any reason (Figure 1). When ICD shock was categorized as appropriate vs. inappropriate, there was a $64 \%$ risk reduction for all-cause death or first inappropriate shock and a $44 \%$ risk reduction for all-cause death or first appropriate shock. The results remained unchanged when stratified by left ventricular ejection fraction or concomitant use of $\beta$-blockers. The mean frequency of all-cause shock was $1.43 \pm 3.53$ in the sotalol group compared to $3.89 \pm 10.65$ in control group. Rate of discontinuation of the drug was about $33 \%$ at one year in the sotalol and placebo groups. Patients receiving sotalol were more likely to have bradycardia and QT prolongation, but only one episode of torsades de pointes (TdP) was reported. Similar efficacy of sotalol was reported in another small scale study of 46 patients. $^{21}$ Similar to sotalol, dofetilide, a pure class $\mathrm{I}_{\mathrm{Kr}}$ blocker, was shown to be effective in increasing the median time to first all-cause ICD shocks in a study by O'Toole et al. ${ }^{27}$ However, dofetilide administration was associated with a high incidence of TdP in this study.

Although most of the patients with ICDs receive $\beta$-blockers as part of a comprehensive medical regimen, it is worth underscoring the importance of $\beta$-adrenergic blockade in prevention of ICD shocks. Simple $\beta$-blockers have been shown to be at least equally or more effective than sotalol in the prevention of ICD shocks. In a small prospective trial of 100 patients with an existing ICD, Kettering et al showed that metoprolol was as effective as sotalol in preventing VT/VF and resultant ICD interventions. ${ }^{23}$ Similarly, in a post hoc analysis of 691 patients with ischemic cardiomyopathy in the Multicenter Automatic Defibrillator Implantation Trial II 
(MADIT-II), patients receiving higher doses of metoprolol, atenolol and carvedilol had a $52 \%$ relative risk reduction for recurrent VT/VF requiring ICD therapy as compared to patients not on $\beta$-blockers. Superior efficacy of metoprolol to sotalol was demonstrated in a small prospective study of 70 patients with an ICD. ${ }^{22}$ The probability of reaching a combined end point of symptomatic recurrence of fast VT or VF, or death was significantly lower at 1 and 2 years in the metoprolol group (83\% and $74 \%$ respectively) as compared to the sotalol group $(47 \%$ and $38 \%$ respectively, $\mathrm{p}=0.004)$. ICD interventions in the form of ATP and shocks were significantly lower in the metoprolol compared to the sotalol arm.

Azimilide is a novel class III drug that blocks both the rapid and slow component of the delayed rectifier cardiac potassium current, and is effective in a variety of supraventricular arrhythmias. ${ }^{28}$ Recent clinical trials have demonstrated its role in the prevention of ICD shocks. In a dose-range, pilot study of 172 ICD patients, Singer at el demonstrated that azimilide reduced the relative risk of appropriate ICD therapy (Shocks and ATP) by $69 \%$ at all administered doses (35 mg, $75 \mathrm{mg}$ or $125 \mathrm{mg}$ ) as compared to placebo at one year follow-up. Azimilide did not have adverse effects on left ventricular function, resting heart rate, defibrillation or pacing thresholds. ${ }^{24}$

The efficacy of azimilide was further investigated by Dorian et al in the large prospective double-blind trial, SHock Inhibition Evaluation with azimiLiDe ${ }^{25}$ (SHIELD) in 633 ICD recipients. The 2 primary end points of this trial were (1) all-cause shocks plus symptomatic tachyarrhythmias terminated by ATP and (2) all-cause shocks. A single secondary end point was all appropriate ICD therapies. Azimilide was tested in $75 \mathrm{mg}$ 
and $125 \mathrm{mg}$ doses. At a median follow-up of 1 year, azimilide significantly reduced the first primary end point of all-cause shocks plus symptomatic arrhythmia terminated by ATP in both doses as compared to placebo (HR: 0.43 for $75 \mathrm{mg}$ dose and HR: 0.53 for $125 \mathrm{mg}$ dose) (Figure 2). There was no statistically significant difference in efficacy between the two doses, and there was a trend toward a reduction in the primary end point of all-cause shock alone with both doses of azimilide.

The secondary end point of all appropriate ICD therapies (shocks or ATPs) was reduced by both 75 and $125 \mathrm{mg} /$ day azimilide $(\mathrm{HR}=0.52$ and 0.38 with $\mathrm{p}=0.017$ and 0.0004 respectively, Figure 2) with a trend toward a more significant effect at the $125 \mathrm{mg}$ dose. Additional analysis revealed that treatment with azimilide led to significant decrease in the incidence of all ICD interventions and all-cause shocks with an increased inter-event interval suggesting a possible benefit in the treatment of electrical storm. This was confirmed by subsequent analysis of SHEILD data by Hohnloser et al who showed that treatment with $75 \mathrm{mg}$ and $125 \mathrm{mg} /$ day azimilide reduced the risk of electrical storm by $37 \%$ and $55 \%$ respectively as compared to placebo. These beneficial effects of azimilide translated into reduced emergency department visits and hospitalizations. ${ }^{29}$

Azimilide was well tolerated as an addition to conventional therapy. About $86 \%$ patient were on concomitant $\beta$-blocker therapy suggesting that benefits of azimilide were over and above traditional therapy. The overall incidence of adverse events and rates of early discontinuation (35-36\%) were similar to placebo. ${ }^{24-26}$ Azimilide therapy led to a dose dependent prolongation of the QT interval, however, TdP was reported in 5 patients without any consequences ${ }^{25}$ One patient had severe but reversible neutropenia with 75 
mg of azimilide. ${ }^{25}$ In the context of the above data, azimilide is the first drug submitted to the Food and Drug Administration for use with an ICD and is currently under review to be used for this indication.

Amiodarone remains one of the most commonly used antiarrhythmic drugs, especially in patients with advanced cardiomyopathy due to its established efficacy and cardiac safety profile compared to other antiarrhythmic drugs. The OPTIC (Optimal Pharmacologic Therapy in Cardioverter Defibrillator Patients) study investigated the efficacy of $\beta$-blocker, sotalol and $\beta$-blocker plus amiodarone in the prevention of ICD shocks. $^{26}$ The OPTIC investigators randomized 412 patients with an ICD to receive $\beta$ blocker alone, sotalol alone, and amiodarone in addition to $\beta$-blocker and followed them for one year. The results showed that the patients treated with sotalol or amiodarone had reduced risk of shock of $56 \%$ compared to $\beta$-blocker alone. In addition, amiodarone plus $\beta$-blocker was more effective than $\beta$-blocker alone $(\mathrm{HR}=0.27, \mathrm{p}<0.001)$ or sotalol $(\mathrm{HR}$ : $0.43, \mathrm{p}=0.02$ ) in preventing both appropriate and inappropriate ICD shocks (Figure 3). Mortality was not significantly different among the three groups and no cases of TdP were reported. Rates of study drug discontinuation at 1 year were $18.2 \%$ for amiodarone, 23.5\% for sotalol and $5.3 \%$ for $\beta$-blocker alone group. Adverse pulmonary, thyroid, and bradycardic events were more common with amiodarone treatment.

Similar to its congener amiodarone, dronedarone was effective in reducing the rate of appropriate ICD intervention during a 30 day follow-up in a small study. ${ }^{30}$

\section{Benefits of Adjuvant antiarrhythmic drug therapy}


Clearly, antiarrhythmic drugs reduce the incidence of both appropriate as well as inappropriate ICD therapies (both ATP and Shock) by more than half. ${ }^{20,25,26}$ Such a reduction in ICD shocks would be expected to decrease emergency department visits as well as the rate of hospitalization. ${ }^{25,29}$ A decrease in the number of ICD discharges also prolongs the battery life of the device. ${ }^{31}$ As such, antiarrhythmic drug therapy result in overall improvement in quality of life of ICD implanted patients. Additionally, most antiarrhythmic drugs tend to prolong the tachycardia cycle length and may render the tachycardia more hemodynamically stable and thus amenable to termination with ATP. ${ }^{32}$ Some antiarrhythmic drugs may reduce the defibrillation threshold (DFT) and facilitate defibrillation of VT/VF as discussed below.

About 10 to $30 \%$ patients with ICD develop electrical storm, defined as three or more episodes of hemodynamically destabilizing VT/VF occurring in a 24-hour period. Development of electrical storm is associated with increased morbidity, and a 40\% 3month mortality. ${ }^{33-35}$ Although, recent clinical trials have suggested role of catheter ablation techniques as a first line treatment for electrical storm, antiarrhythmic drugs still remain the cornerstone for the therapy for electrical storm. Reversal of precipitating factors, optimization of $\beta$-blocker therapy and addition of intravenous amiodarone followed by oral maintenance dosing is required in most cases to abort and prevent recurrent ventricular arrhythmia. ${ }^{33,36}$ As outlined above, the investigational agent azimilide has been shown to reduce risk of electrical storm by $37-55 \% .{ }^{37}$ The principle advantages of adjuvant antiarrhythmic drug therapy can be summarized as in Table 1.

\section{Drug-device Interaction}


A great deal of caution needs to be exercised when a new antiarrhythmic drug is started in a patient with an implanted device. Potential adverse drug-device interactions are listed in Table 2.

One of the most important drug-device interactions is a drug-induced increase in defibrillation and pacing thresholds leading to failure of treatment of life threatening arrhythmia. Although most antiarrhythmic drugs increase the defibrillation threshold (DFT), some may lower it. In a sub-study of 94 patients from OPTIC, amiodarone plus $\beta$ blocker therapy led to a small but statistically significant increase (1.29 J) in DFT after 813 weeks of therapy. ${ }^{38}$ In contrast, treatment with sotalol and $\beta$-blocker was associated with decrease in DFT by $0.89 \mathrm{~J}$ and $1.67 \mathrm{~J}$ respectively. Careful testing of DFTs should be performed in all the patients, with special attention to those who have monophasic waveform ICDs, those with an epicardial lead system $^{39}$, patients with a high DFT at baseline, and patients treated with high dose, ${ }^{40}$ chronic amiodarone. ${ }^{41-44}$

Azimilide has been shown to have minimal effects on the DFT or pacing thresholds in ICD patients. ${ }^{24,45}$ Similarly, dronedarone has been shown to have no effect on defibrillation safety margin or pacing thresholds at its therapeutic dose or higher. ${ }^{30,46}$

Antiarrhythmic drugs are usually increase the cycle length of VT, which improve hemodynamic tolerability and effectiveness of ATP in most situations. The downside is that the drugs like amiodarone and sotalol may slow the tachycardia rate to such a degree that it becomes lower that the programmed tachycardia detection rate of the ICD leading to failure to sense VT. ${ }^{47}$ Appropriate adjustments in the detection algorithm are necessary when adjuvant antiarrhythmic drugs are instituted. Antiarrhythmic drugs, especially Class 
IC agents, may also affect the morphology of the QRS complex and thus impact morphology sensing and rhythm stability criterion leading to incorrect rhythm interpretation by the ICD and resultant inappropriate treatment. ${ }^{48}$

Drug induced proarrhythmia, especially $\mathrm{TdP}$, is rare but serious problem when drugs with Class III effects like azimilide, sotalol, dofetilide and amiodarone are used, especially in patients with compromised repolarization reserve. ${ }^{49}$ Extra-cardiac side effects of antiarrhythmic drugs like amiodarone are a limitation to its long term use. This may be less of an issue with new drugs like dronedarone or azimilide. ${ }^{46}$

\section{Expert Opinion}

In conclusion, adjuvant antiarrhythmic drug therapy should be considered an integral part of the management of patients with an ICD. Unanswered questions are: 1) Which patients should receive adjuvant antiarrhytmic drug therapy? 2) When to start the therapy? 3) What drugs to start? 4) When to consider catheter based ablation techniques?

The majority of clinical trials outlined above enrolled patients for whom the ICD was implanted for secondary prevention of SCD. Similar evidence in patients who have received the ICD for primary prevention is lacking. Such patients appear to have fewer

device activations. ${ }^{50,51}$ In the context of a lower risk population, adjuvant antiarrhythmic drug therapy should be started only if one or more ICD shocks have been delivered, with the expectation that well designed therapy can reduce ICD shocks and improve quality of life. The timing of antiarrhythmic drug therapy in patients should always be based on best physician judgment and patient preference. 
It should be emphasized here that no drug has achieved approval for the prevention of ICD shocks, and we have no data to support early, prophylactic use. Although starting antiarrhythmic drug therapy before an ICD shock is delivered might be valuable, it should be kept in mind that antiarrhythmic drug therapy itself carries substantial risk.

When patients need drugs because of frequent shocks, the weight of evidence supports optimizing $\beta$-blocker therapy. If they are ineffective or poorly tolerated, amiodarone, azimilide, or sotalol may provide benefit. Any antiarrhythmic drug prescribed to treat serious ventricular arrhythmias, including those that have triggered an ICD shock, should be started under observation not only to observe for toxicity, but also to gauge efficacy. If proarrhythmia occurs, it tends to become manifest during the early stages of therapy, as drug concentrations approach steady state.

Catheter based mapping and ablation techniques have been considered a last resort treatment for patients with recurrent VT refractory to adjuvant drug therapy. ${ }^{52}$ Although recent clinical trials support the role of catheter ablation techniques as a prime line treatment for prevention of recurrent ICD therapies including electrical storm, these techniques are invasive and results are operator dependent. ${ }^{53-55}$ Data supporting the use of catheter ablation therapy are limited and do not address issues such as quality of life and cost. We believe that antiarrhythmic drugs remain first line therapy for prevention of ICD shocks for most patients. ${ }^{56}$ 


\section{Reference List}

(1) DiMarco JP. Implantable cardioverter-defibrillators. N Engl J Med. 2003;349:1836-1847.

(2) Reiffel JA. Drug and drug-device therapy in heart failure patients in the postCOMET and SCD-HeFT era. J Cardiovasc Pharmacol Ther. 2005;10 Suppl 1:S45-S58.

(3) Mirowski M, Reid PR, Mower MM et al. Termination of malignant ventricular arrhythmias with an implanted automatic defibrillator in human beings. $N$ Engl $J$ Med. 1980;303:322-324.

(4) Epstein AE, DiMarco JP, Ellenbogen KA et al. ACC/AHA/HRS 2008 Guidelines for Device-Based Therapy of Cardiac Rhythm Abnormalities: a report of the American College of Cardiology/American Heart Association Task Force on Practice Guidelines (Writing Committee to Revise the ACC/AHA/NASPE 2002 Guideline Update for Implantation of Cardiac Pacemakers and Antiarrhythmia Devices): developed in collaboration with the American Association for Thoracic Surgery and Society of Thoracic Surgeons. Circulation. 2008;117:e350-e408.

(5) Al-Khatib SM, LaPointe NM, Curtis LH et al. Outpatient prescribing of antiarrhythmic drugs from 1995 to 2000. Am J Cardiol. 2003;91:91-94. 
(6) Hine LK, Gross TP, Kennedy DL. Outpatient antiarrhythmic drug use from 1970 through 1986. Arch Intern Med. 1989;149:1524-1527.

(7) Zhan C, Baine WB, Sedrakyan A, Steiner C. Cardiac device implantation in the United States from 1997 through 2004: a population-based analysis. J Gen Intern Med. 2008;23 Suppl 1:13-19.

(8) Patel C, Yan GX, Kocovic D, Kowey PR. Should catheter ablation be the preferred therapy for reducing ICD shocks?: Ventricular tachycardia ablation versus drugs for preventing ICD shocks: role of adjuvant antiarrhythmic drug therapy. Circ Arrhythm Electrophysiol. 2009;2:705-711.

(9) Dorian P, Philippon F, Thibault B et al. Randomized controlled study of detection enhancements versus rate-only detection to prevent inappropriate therapy in a dual-chamber implantable cardioverter-defibrillator. Heart Rhythm. 2004;1:540547.

(10) Nanthakumar K, Paquette M, Newman D et al. Inappropriate therapy from atrial fibrillation and sinus tachycardia in automated implantable cardioverter defibrillators. Am Heart J. 2000;139:797-803.

(11) Rosenqvist M, Beyer T, Block M, den DK, Minten J, Lindemans F. Adverse events with transvenous implantable cardioverter-defibrillators: a prospective 
multicenter study. European 7219 Jewel ICD investigators. Circulation. 1998;98:663-670.

(12) Ahmad M, Bloomstein L, Roelke M, Bernstein AD, Parsonnet V. Patients' attitudes toward implanted defibrillator shocks. Pacing Clin Electrophysiol. 2000;23:934-938.

(13) Pelletier D, Gallagher R, Mitten-Lewis S, McKinley S, Squire J. Australian implantable cardiac defibrillator recipients: quality-of-life issues. Int J Nurs Pract. 2002;8:68-74.

(14) Dougherty CM. Psychological reactions and family adjustment in shock versus no shock groups after implantation of internal cardioverter defibrillator. Heart Lung. $1995 ; 24: 281-291$.

(15) Heller SS, Ormont MA, Lidagoster L, Sciacca RR, Steinberg S. Psychosocial outcome after ICD implantation: a current perspective. Pacing Clin Electrophysiol. 1998;21:1207-1215.

(16) Sola CL, Bostwick JM. Implantable cardioverter-defibrillators, induced anxiety, and quality of life. Mayo Clin Proc. 2005;80:232-237.

(17) Greene HL. Interactions between pharmacologic and nonpharmacologic antiarrhythmic therapy. Am J Cardiol. 1996;78:61-66. 
(18) Movsowitz C, Marchlinski FE. Interactions between implantable cardioverterdefibrillators and class III agents. Am J Cardiol. 1998;82:41I-48I.

(19) Steinberg JS, Martins J, Sadanandan S et al. Antiarrhythmic drug use in the implantable defibrillator arm of the Antiarrhythmics Versus Implantable Defibrillators (AVID) Study. Am Heart J. 2001;142:520-529.

(20) Pacifico A, Hohnloser SH, Williams JH et al. Prevention of implantabledefibrillator shocks by treatment with sotalol. d,1-Sotalol Implantable Cardioverter-Defibrillator Study Group. N Engl J Med. 1999;340:1855-1862.

(21) Kuhlkamp V, Mewis C, Mermi J, Bosch RF, Seipel L. Suppression of sustained ventricular tachyarrhythmias: a comparison of d,l-sotalol with no antiarrhythmic drug treatment. J Am Coll Cardiol. 1999;33:46-52.

(22) Seidl K, Hauer B, Schwick NG, Zahn R, Senges J. Comparison of metoprolol and sotalol in preventing ventricular tachyarrhythmias after the implantation of a cardioverter/defibrillator. Am J Cardiol. 1998;82:744-748.

(23) Kettering K, Mewis C, Dornberger V, Vonthein R, Bosch RF, Kuhlkamp V. Efficacy of metoprolol and sotalol in the prevention of recurrences of sustained ventricular tachyarrhythmias in patients with an implantable cardioverter defibrillator. Pacing Clin Electrophysiol. 2002;25:1571-1576. 
(24) Singer I, Al-Khalidi H, Niazi I et al. Azimilide decreases recurrent ventricular tachyarrhythmias in patients with implantable cardioverter defibrillators. $J$ Am Coll Cardiol. 2004;43:39-43.

(25) Dorian P, Borggrefe M, Al-Khalidi HR et al. Placebo-controlled, randomized clinical trial of azimilide for prevention of ventricular tachyarrhythmias in patients with an implantable cardioverter defibrillator. Circulation. 2004;110:3646-3654.

(26) Connolly SJ, Dorian P, Roberts RS et al. Comparison of beta-blockers, amiodarone plus beta-blockers, or sotalol for prevention of shocks from implantable cardioverter defibrillators: the OPTIC Study: a randomized trial. JAMA. 2006;295:165-171.

(27) O'Toole M, O'Neill G, Kluger J, Bonney S, Billing C. Efficacy and safety of oral dofetilide in patients with an implantable defibrillator: A multi-center study. Circulation. 1999;100:I-794.

(28) Connolly SJ, Schnell DJ, Page RL, Wilkinson WE, Marcello SR, Pritchett EL. Dose-response relations of azimilide in the management of symptomatic, recurrent, atrial fibrillation. Am J Cardiol. 2001;88:974-979.

(29) Dorian P, Al-Khalidi HR, Hohnloser SH et al. Azimilide reduces emergency department visits and hospitalizations in patients with an implantable 
cardioverter-defibrillator in a placebo-controlled clinical trial. J Am Coll Cardiol. 2008;52:1076-1083.

(30) Kowey PR, Singh BN. Dronedarone in patients with implantable defibrillators. Heart Rhythm Society 2004 Scientific Session, Late breaking Clinical Trials Oral Presentation. 2004.

(31) Dorian P. Combination ICD and drug treatments-best options. Resuscitation. 2000;45:S3-S6.

(32) Mazur A, Anderson ME, Bonney S, Roden DM. Pause-dependent polymorphic ventricular tachycardia during long-term treatment with dofetilide: a placebocontrolled, implantable cardioverter-defibrillator-based evaluation. J Am Coll Cardiol. 2001;37:1100-1105.

(33) Credner SC, Klingenheben T, Mauss O, Sticherling C, Hohnloser SH. Electrical storm in patients with transvenous implantable cardioverter-defibrillators: incidence, management and prognostic implications. J Am Coll Cardiol. 1998;32:1909-1915.

(34) Exner DV, Pinski SL, Wyse DG et al. Electrical storm presages nonsudden death: the antiarrhythmics versus implantable defibrillators (AVID) trial. Circulation. 2001;103:2066-2071. 
(35) Villacastin J, Almendral J, Arenal A et al. Incidence and clinical significance of multiple consecutive, appropriate, high-energy discharges in patients with implanted cardioverter-defibrillators. Circulation. 1996;93:753-762.

(36) Greene M, Newman D, Geist M, Paquette M, Heng D, Dorian P. Is electrical storm in ICD patients the sign of a dying heart? Outcome of patients with clusters of ventricular tachyarrhythmias. Europace. 2000;2:263-269.

(37) Hohnloser SH, Al-Khalidi HR, Pratt CM et al. Electrical storm in patients with an implantable defibrillator: incidence, features, and preventive therapy: insights from a randomized trial. Eur Heart J. 2006;27:3027-3032.

(38) Hohnloser SH, Dorian P, Roberts R et al. Effect of amiodarone and sotalol on ventricular defibrillation threshold: the optimal pharmacological therapy in cardioverter defibrillator patients (OPTIC) trial. Circulation. 2006;114:104-109.

(39) Kuhlkamp V, Mewis C, Suchalla R, Mermi J, Dornberger V, Seipel L. Effect of amiodarone and sotalol on the defibrillation threshold in comparison to patients without antiarrhythmic drug treatment. Int J Cardiol. 1999;69:271-279.

(40) Zhou L, Chen BP, Kluger J, Fan C, Chow MS. Effects of amiodarone and its active metabolite desethylamiodarone on the ventricular defibrillation threshold. $J$ Am Coll Cardiol. 1998;31:1672-1678. 
(41) Wood MA, Ellenbogen KA. Follow-up defibrillator testing for antiarrhythmic drugs: probability and uncertainty. Circulation. 2006;114:98-100.

(42) Epstein AE, Ellenbogen KA, Kirk KA, Kay GN, Dailey SM, Plumb VJ. Clinical characteristics and outcome of patients with high defibrillation thresholds. A multicenter study. Circulation. 1992;86:1206-1216.

(43) Fain ES, Lee JT, Winkle RA. Effects of acute intravenous and chronic oral amiodarone on defibrillation energy requirements. Am Heart J. 1987;114:8-17.

(44) Pelosi F, Jr., Oral H, Kim MH et al. Effect of chronic amiodarone therapy on defibrillation energy requirements in humans. J Cardiovasc Electrophysiol. 2000;11:736-740.

(45) Qi XQ, Newman D, Dorian P. Azimilide decreases defibrillation voltage requirements and increases spatial organization during ventricular fibrillation. $J$ Interv Card Electrophysiol. 1999;3:61-67.

(46) Patel C, Yan GX, Kowey PR. Droendarone. Circulation. 2009;120:636-644.

(47) Bansch D, Castrucci M, Bocker D, Breithardt G, Block M. Ventricular tachycardias above the initially programmed tachycardia detection interval in patients with implantable cardioverter-defibrillators: incidence, prediction and significance. J Am Coll Cardiol. 2000;36:557-565. 
(48) Rajawat YS, Patel VV, Gerstenfeld EP, Nayak H, Marchlinski FE. Advantages and pitfalls of combining device-based and pharmacologic therapies for the treatment of ventricular arrhythmias: observations from a tertiary referral center. Pacing Clin Electrophysiol. 2004;27:1670-1681.

(49) Wolbrette DL. Risk of proarrhythmia with class III antiarrhythmic agents: sexbased differences and other issues. Am J Cardiol. 2003;91:39D-44D.

(50) Bardy GH, Lee KL, Mark DB et al. Amiodarone or an implantable cardioverterdefibrillator for congestive heart failure. N Engl J Med. 2005;352:225-237.

(51) Kadish A, Dyer A, Daubert JP et al. Prophylactic defibrillator implantation in patients with nonischemic dilated cardiomyopathy. $N$ Engl J Med. 2004;350:2151-2158.

(52) Morady F. Radio-frequency ablation as treatment for cardiac arrhythmias. N Engl J Med. 1999;340:534-544.

(53) Carbucicchio C, Santamaria M, Trevisi N et al. Catheter ablation for the treatment of electrical storm in patients with implantable cardioverter-defibrillators: shortand long-term outcomes in a prospective single-center study. Circulation. 2008;117:462-469. 
(54) Reddy VY, Reynolds MR, Neuzil P et al. Prophylactic catheter ablation for the prevention of defibrillator therapy. $N$ Engl J Med. 2007;357:2657-2665.

(55) Weinstock J, Wang PJ, Homoud MK, Link MS, Estes NA, III. Clinical results with catheter ablation: AV junction, atrial fibrillation and ventricular tachycardia. J Interv Card Electrophysiol. 2003;9:275-288.

(56) Estes NA, III. Ablation after ICD implantation--bridging the gap between promise and practice. $N$ Engl J Med. 2007;357:2717-2719. 
Tables:

Table 1: Clinical trials summarizing benefits of adjuvant antiarrhythmic drug therapy.

\begin{tabular}{|c|c|c|c|c|c|}
\hline Study & Drug/Dose & $\begin{array}{l}\text { N per } \\
\text { group }\end{array}$ & $\begin{array}{l}\text { Follow- } \\
\text { up }\end{array}$ & Primary Endpoint & Secondary Endpoint \\
\hline $\begin{array}{l}\text { Pacifico } \\
\text { et al. }\end{array}$ & $\begin{array}{l}\text { Sotalol } \\
(207 \pm 55 \mathrm{mg}) \\
\text { Vs. } \\
\text { Placebo }\end{array}$ & 151 & $\begin{array}{l}12 \\
\text { months }\end{array}$ & $\begin{array}{l}\text { All-cause death or all- } \\
\text { cause ICD shock: } \\
\text { Sotalol: } 44 \% *(\mathrm{HR}: \\
0.52) \\
\text { Placebo: } 56 \%\end{array}$ & $\begin{array}{l}\text { Mean frequency of } \\
\text { shocks due to any } \\
\text { cause: } \\
\text { Sotalol: } 1.43 \pm \\
3.53^{*} \\
\text { Placebo: } 3.89 \pm \\
10.65\end{array}$ \\
\hline $\begin{array}{l}\text { Kuhlkamp } \\
\text { et } \mathrm{al}^{21}\end{array}$ & $\begin{array}{l}\text { Sotalol } \\
\text { ( } 80 \text { to } 400 \\
\text { mg) } \\
\text { Vs. placebo }\end{array}$ & $\approx 46$ & $\begin{array}{l}12 \\
\text { months }\end{array}$ & $\begin{array}{l}\text { Recurrence of VT/VF: } \\
\text { Sotalol: } 32.6 \% * \\
\text { Placebo: } 53.2 \%\end{array}$ & $\begin{array}{l}\text { Total mortality: } \\
\text { Same across the } \\
\text { groups }\end{array}$ \\
\hline $\begin{array}{l}\text { Seidl et } \\
\mathrm{al}^{22}\end{array}$ & $\begin{array}{l}\text { Metoprolol } \\
(104 \pm 37 \mathrm{mg}) \\
\text { Vs. Sotalol } \\
(242 \pm 109 \mathrm{mg})\end{array}$ & 35 & $\begin{array}{l}26 \pm 16 \\
\text { months }\end{array}$ & $\begin{array}{l}\text { Appropriate ICD } \\
\text { therapy: } \\
\text { VT treated by ATPs: } \\
\text { Metoprolol: } 20 \% * \\
\text { Sotalol: } 49 \% \\
\text { Fast VT/VF treated by } \\
\text { ICD shocks: } \\
\text { Metoprolol: } 20 \% * \\
\text { Sotalol: } 54 \%\end{array}$ & $\begin{array}{l}\text { Total mortality: } \\
\text { Metoprolol: } 3 \\
\text { deaths } \\
\text { Sotalol: } 6 \text { deaths } \\
\text { Actuarial survival } \\
\text { rate: } \\
\text { Not different } \\
\text { between the two } \\
\text { groups }\end{array}$ \\
\hline $\begin{array}{l}\text { Kettering } \\
\text { et al } \mathrm{al}^{23}\end{array}$ & $\begin{array}{l}\text { Metoprolol } \\
(108 \pm 44 \mathrm{mg}) \\
\text { Vs. Sotalol } \\
(319 \pm 91 \mathrm{mg})\end{array}$ & 50 & $\begin{array}{l}727 \\
\text { days }\end{array}$ & $\begin{array}{l}\text { Recurrent VT/VF } \\
\text { requiring ICD } \\
\text { Therapy: } \\
\text { Metoprolol: } 66 \% \\
\text { Sotalol: } 60 \% \\
\text { Event free survival not } \\
\text { different between } \\
\text { groups }\end{array}$ & $\begin{array}{l}\text { Total mortality: } \\
\text { Metoprolol: } 8 \\
\text { deaths } \\
\text { Sotalol: } 6 \text { deaths } \\
\text { Not different } \\
\text { between the two } \\
\text { groups }\end{array}$ \\
\hline $\begin{array}{l}\text { Singer et } \\
\mathrm{al}^{24}\end{array}$ & $\begin{array}{l}\text { Azimilide } 35, \\
75 \text { or } 125 \mathrm{mg} \\
\text { Vs. placebo }\end{array}$ & $\begin{array}{l}\approx 35- \\
46\end{array}$ & $\begin{array}{l}374 \\
\text { days }\end{array}$ & $\begin{array}{l}\text { Frequency of } \\
\text { appropriate ICD } \\
\text { shocks and ATPs: } \\
\text { Placebo: } 36 \\
35 \mathrm{mg} \text { AZ: } 10^{*} \\
75 \mathrm{mg} \text { AZ: } 12^{*} \\
125 \mathrm{mg} \text { AZ: } 9 * \text { per } \\
\text { patient-year. (HR: } \\
0.31)\end{array}$ & \\
\hline
\end{tabular}




\begin{tabular}{|c|c|c|c|c|c|}
\hline $\begin{array}{l}\text { Dorian et } \\
\mathrm{al}^{25} \\
\text { SHIELD }\end{array}$ & $\begin{array}{l}\text { Azimilide } \\
75,125 \mathrm{mg} \\
\text { Vs. placebo }\end{array}$ & $\begin{array}{l}\text { ₹199- } \\
214\end{array}$ & 1 year & $\begin{array}{l}\text { All-cause shock and } \\
\text { ATP: } \\
75 \mathrm{mg} \text { AZ: HR }=0.43 * \\
125 \mathrm{mg} \text { AZ: HR=0.53* } \\
\text { as compared to placebo } \\
\text { All-cause shock: } \\
\text { Tread towards } \\
\text { reduction in treatment } \\
\text { group }\end{array}$ & $\begin{array}{l}\text { Appropriate ICD } \\
\text { therapy: } \\
75 \mathrm{mg} \text { AZ: } \\
\mathrm{HR}=0.52^{*} \\
125 \mathrm{mg} \mathrm{AZ:} \\
\mathrm{HR}=0.38^{*} \\
\text { as compared to } \\
\text { placebo }\end{array}$ \\
\hline $\begin{array}{l}\text { Connolly } \\
\text { et al } \\
\text { OPTIC }\end{array}$ & $\begin{array}{l}\text { B-blocker vs. } \\
\text { Sotalol vs. } \\
\text { Amiodarone } \\
\text { plus } \beta \text { - } \\
\text { blocker }\end{array}$ & $\begin{array}{l}134- \\
138\end{array}$ & 1 year & $\begin{array}{l}\text { All-cause ICD shock: } \\
\beta \text {-blocker: } 38.5 \% \\
\text { Sotalol: } 24.3 \% \\
\text { Amiodarone plus } \beta \text { - } \\
\text { blocker: } 10.3 \% * \text { (HR: } \\
0.27 \text { Vs. } \beta \text {-blocker, } \\
\text { HR: } 0.43 \text { Vs. sotalol) }\end{array}$ & \\
\hline
\end{tabular}

*, significant p value; AZ, azimilide; ATPs, antitachycardia pacing; HR, hazard ratio; ICD, implantable cardioverter defibrillator; VT, ventricular tachycardia; VF, ventricular fibrillation; SHIELD, Shock Inhibition Evaluation with azimiLiDe; OPTIC, Optimal Pharmacologic Therapy in Cardioverter Defibrillator Patients. Reproduced with permission from reference 8. 
Table 2: Benefits and Pitfalls of adjuvant antiarrhythmic drug therapy in ICD patients.

\section{Advantages and pitfalls of adjuvant antiarrhythmic drug therapy in patients with ICD}

\section{Pros:}

- Decrease in appropriate ICD shocks due to suppression of recurrent VT/VF

-Decrease in inappropriate ICD shocks due to reduced frequency and better rate control of supraventricular rhythm

-Slowing of tachycardia leading to improved hemodynamic tolerance

-Slowing of rate of tachycardia facilitating successful termination by ATP

-Prolongation of ICD battery life

-Decrease in frequency of symptomatic non-sustained ventricular arrhythmias

-Prevention and better treatment of electrical storm

-Improved quality of life and sense of well-being

-Reduced defibrillation threshold facilitating easier defibrillation

-Improved control of maximal sinus rate

-Reduced rate of recurrent ICD related hospitalizations

\section{Cons:}

-Interference in ICD function due to

-Increase in defibrillation threshold

-Increase in pacing threshold

-Interference in accurate arrhythmia detection due to 


\begin{tabular}{|c|}
\hline -Slowing of rate of Ventricular tachycardia \\
-Decrease in amplitude of electrocardiogram interfering with sensing \\
-Limited effectiveness of rate stability criterion \\
-Adverse effects \\
-Cardiac: \\
-bradyarrhythmia \\
-Torsades de pointes \\
-Impairment of myocardial function \\
-Extra-cardiac toxicity
\end{tabular}

Reproduced with permission from reference 8. 


\section{Figure Legends:}

Figure 1: The Kaplan-Meier time-to-event curves for combined end point of all-cause death or all-cause shock in control and sotalol group. Treatment with sotalol reduced the relative risk of combined end point by $48 \%$. Reproduced with permission from reference ${ }^{20}$.

Figure 2: A: Effect of azimilide (AZ) on all-cause shocks plus symptomatic tachyarrhythmias terminated by antitachycardia pacing. Treatment with 75 $\mathrm{mg} /$ day and $125 \mathrm{mg} /$ day azimilide significantly reduced risk of all-cause shocks and symptomatic tachyarrhythmia by $57 \%$ and $47 \%$ respectively. B: Effect of azimilide on all appropriate ICD therapies. Treatment with $75 \mathrm{mg} /$ day and 125 $\mathrm{mg}$ /day of azimilide significantly reduced the risk of all appropriate ICD therapies by $48 \%$ and $62 \%$ respectively. Reproduced with permission from reference ${ }^{25}$.

Figure 3: Cumulative risk of shock in all three treatment groups. Amiodarone plus $\beta$ blocker significantly reduced the risk of shock compared with $\beta$-blocker alone (HR: $0.27, \mathrm{p}<0.001)$ and sotalol (HR: 0.43, $\mathrm{p}=0.02)$. Reproduced with permission from reference ${ }^{26}$. 
Figure 1.

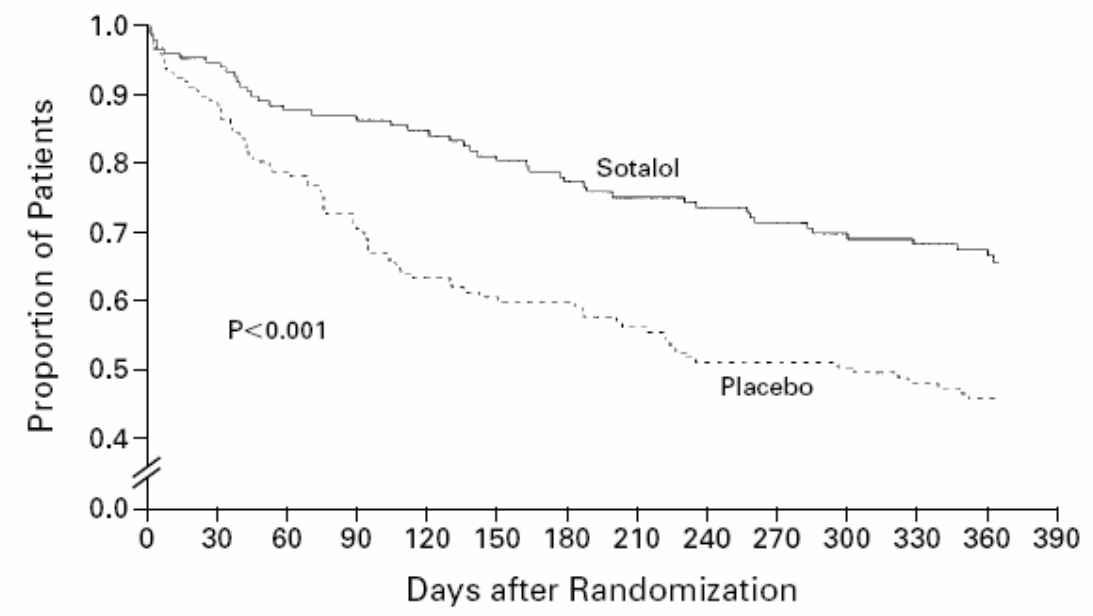

NO. AT RISK

$\begin{array}{lrrrrrrrrrrrrr}\text { Placebo } & 151 & 129 & 114 & 101 & 90 & 84 & 84 & 77 & 70 & 70 & 69 & 65 & 49 \\ \text { Sotalol } & 151 & 136 & 123 & 119 & 115 & 109 & 104 & 101 & 99 & 95 & 91 & 90 & 70\end{array}$

$\begin{array}{llllllllllllll}\text { Sotalol } & 151 & 136 & 123 & 119 & 115 & 109 & 104 & 101 & 99 & 95 & 91 & 90 & 70\end{array}$ 
Figure 2.
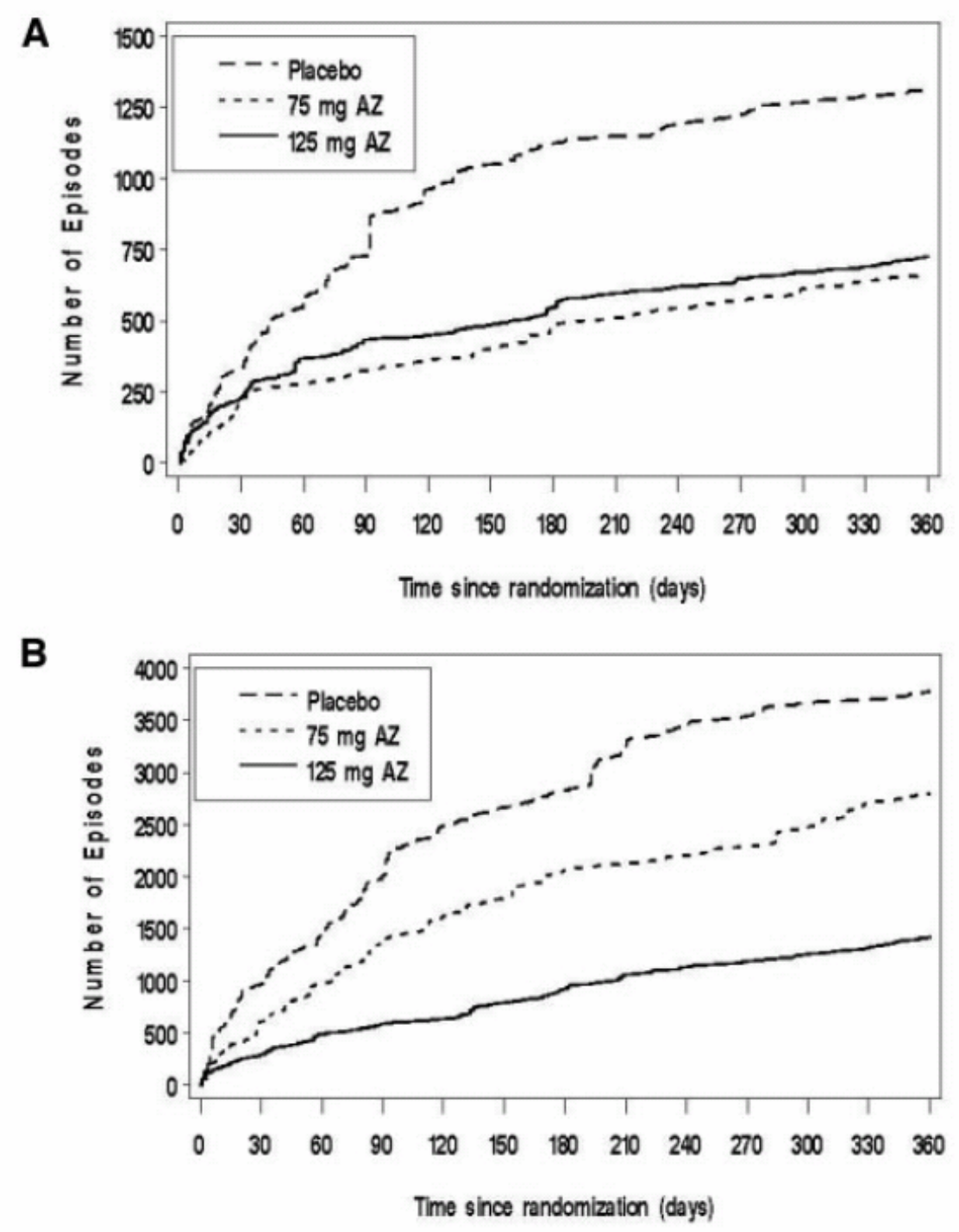
Figure 3.

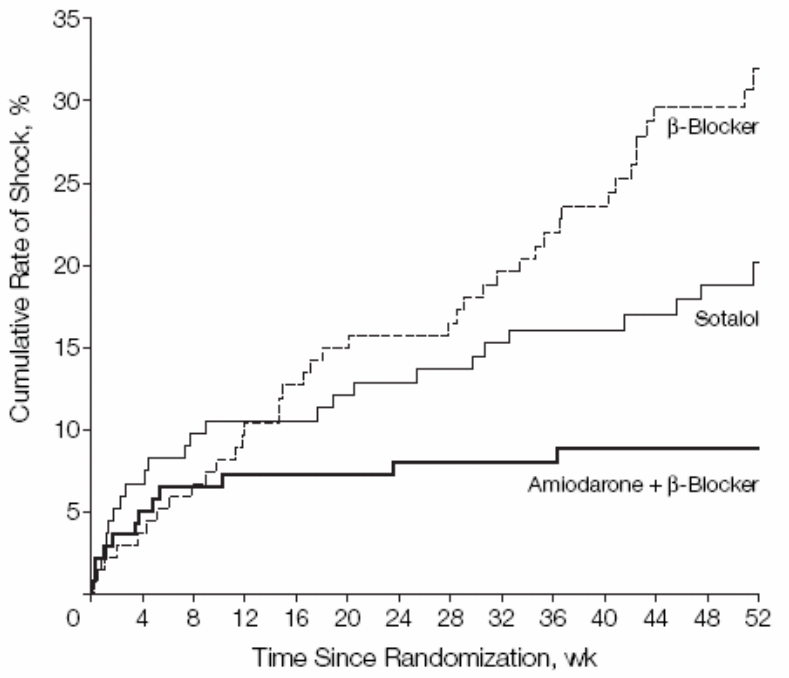

\begin{tabular}{|c|c|c|c|c|c|}
\hline \multicolumn{6}{|l|}{ No. at Risk } \\
\hline$\beta$-Blocker & 138 & 119 & 109 & 91 & 42 \\
\hline Sotalol & 134 & 118 & 108 & 94 & 35 \\
\hline Amiodarone $+\beta$-Blocker & 140 & 124 & 115 & 106 & 56 \\
\hline
\end{tabular}


